\title{
Calcium Increases in Retinal Glial Cells Evoked by Light- Induced Neuronal Activity
}

\author{
Eric A. Newman \\ Department of Neuroscience, University of Minnesota, Minneapolis, Minnesota 55455
}

Electrical stimulation of neurons in brain slices evokes increases in cytoplasmic $\mathrm{Ca}^{2+}$ in neighboring astrocytes. The present study tests whether similar neuron-to-glial signaling occurs in the isolated rat retina in response to light stimulation. Results demonstrate that Müller cells, the principal retinal glial cells, generate transient increases in $\mathrm{Ca}^{2+}$ under constant illumination. A flickering light stimulus increases the occurrence of these $\mathrm{Ca}^{2+}$ transients. Antidromic activation of ganglion cell axons also increases the generation of Müller cell $\mathrm{Ca}^{2+}$ transients. The increases in $\mathrm{Ca}^{2+}$ transients evoked by light and antidromic stimulation are blocked by the purinergic antagonist suramin and by TTX. The addition of adenosine greatly potentiates the response to light, with light $\mathrm{ON}$ evoking large $\mathrm{Ca}^{2+}$ increases in Müller cells. Suramin, apyrase (an ATP-hydrolyzing enzyme), and TTX substantially reduce the adenosine-potentiated response. NMDA, metabotropic glutamate, $\mathrm{GABA}_{\mathrm{B}}$, and muscarinic receptor antagonists, in contrast, are mainly ineffective in blocking the response. Light-evoked $\mathrm{Ca}^{2+}$ responses begin in Müller cell processes within the inner plexiform (synaptic) layer of the retina and then spread into cell endfeet at the inner retinal surface. These results represent the first demonstration that $\mathrm{Ca}^{2+}$ increases in CNS glia can be evoked by a natural stimulus (light flashes). The results suggest that neuron-to-glia signaling in the retina is mediated by neuronal release of ATP, most likely from amacrine and/or ganglion cells, and that the response is augmented under pathological conditions when adenosine levels increase.

Key words: calcium; astrocyte; Müller cell; glial cell; retina; ATP; adenosine; light response; ganglion cell

\section{Introduction}

A bidirectional dialogue takes place between neurons and glial cells in the CNS. In brain slices, neuron-to-glia signaling has been observed by a number of laboratories (for review, see Newman, 2003b; Schipke and Kettenmann, 2004). Electrical activation of neurons results in $\mathrm{Ca}^{2+}$ increases in astrocytes, a response mediated by neuronal release of glutamate (Porter and McCarthy, 1996; Pasti et al., 1997), GABA (Kang et al., 1998), or acetylcholine (Araque et al., 2002), and activation of metabotropic receptors on glial cells. Glia to neuron signaling has also been observed. Stimulation of astrocytes results in the release of "gliotransmitters," primarily glutamate, and modulation of the electrical excitability of neighboring neurons (for review, see Volterra et al., 2002; Newman, 2003b; Fellin and Carmignoto, 2004; Newman, 2005). This bidirectional communication between neurons and glia enables glial cells to modulate synaptic transmission and raises the intriguing possibility that glia participate in information processing in the CNS.

Glia-to-neuron signaling also has been observed in the retina. After a rise in $\mathrm{Ca}^{2+}$, glial cells release transmitters that can either facilitate or depress the light-evoked spike activity of ganglion

Received Dec. 13, 2004; revised April 25, 2005; accepted April 25, 2005

This work was supported by National Institutes of Health Grant EY004077. I thank P. Ceelen for technical assistance and J. I. Gepner, M. Metea, and K. R. Zahs for helpful discussions.

Correspondence should be addressed to Dr. Eric A. Newman, Department of Neuroscience, University of Minnesota, 6-145 Jackson Hall, 321 Church Street Southeast, Minneapolis, MN 55455. E-mail: ean@umn.edu.

DOI:10.1523/JNEUROSCI.1354-05.2005

Copyright $\odot 2005$ Society for Neuroscience $\quad$ 0270-6474/05/255502-09\$15.00/0 cells, the retinal neurons that project to the brain (Newman and Zahs, 1998). This interaction may be mediated by glial modulation of synaptic transmission onto ganglion cells (Newman, 2004). Retinal glial cells can also inhibit ganglion cells directly, a response mediated by the release of ATP from Müller cells (Newman, 2003a), the principal glial cells of the retina (Newman and Reichenbach, 1996; Newman, 2001a). ATP released from Müller cells is rapidly converted to adenosine by ectoenzymes, resulting in the activation of ganglion cell $\mathrm{A}_{1}$ receptors and to the opening of ganglion cell $\mathrm{K}^{+}$channels.

Although robust glia-to-neuron communication is observed in the retina, it remains unclear whether the reciprocal neuronto-glia signaling also occurs. Experimental application of agonists has been shown to evoke $\mathrm{Ca}^{2+}$ increases in retinal glial cells (Newman and Zahs, 1997; Newman, 2001b; Reifel Saltzberg et al., 2003). However, the physiological stimuli capable of activating these cells are not known.

The present study was undertaken to determine whether neurons, when stimulated by light flashes, signal retinal glial cells and elicit increases in glial $\mathrm{Ca}^{2+}$. The results demonstrate that light stimulation evokes $\mathrm{Ca}^{2+}$ increases in retinal Müller cells and indicates that neuron-to-glia signaling is mediated by a lightevoked release of ATP from neurons.

\section{Materials and Methods}

Retinal preparations. Experiments were performed on acutely isolated retinas of male Long-Evans rats (175-300 g). Two preparations were used: the whole-mount retina and everted eyecup. One of the two preparations proved technically superior for different experiments, but all 


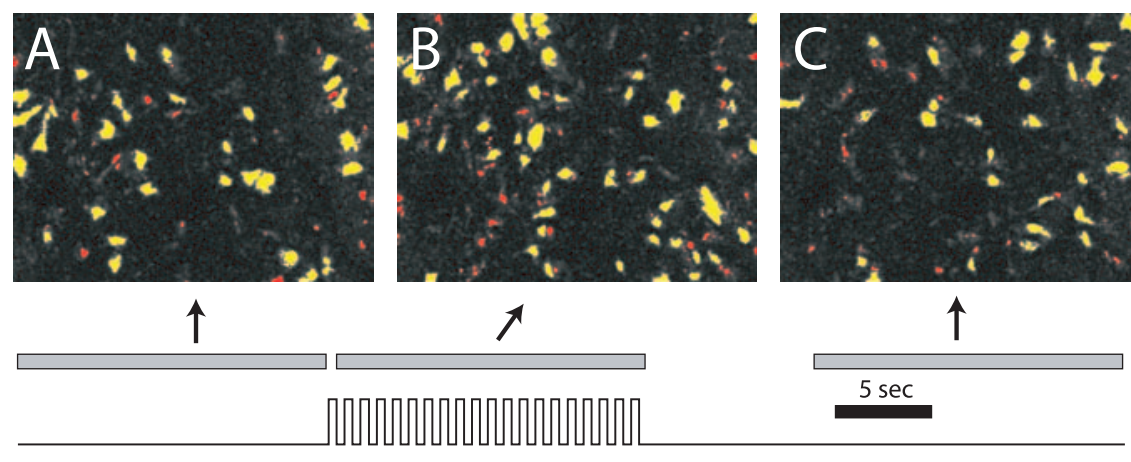

Figure 1. Calcium transients in Müller cells. $\boldsymbol{A}-\boldsymbol{C}$ show $\mathrm{Ca}^{2+}$ fluorescence ratio images of the retina that have been thresholded. The red and yellow areas indicate retinal regions in which $\mathrm{Ca}^{2+}$ has increased transiently during the acquisition period. The red areas are regions $<12 \mu \mathrm{m}^{2}$. The yellow areas exceed this size and are scored as $\mathrm{Ca}^{2+}$ transients within Müller cells. Images in $\boldsymbol{A}-\boldsymbol{C}$ were acquired before, during, and after a flickering light stimulus, respectively. The light stimulus protocol, a 16 s episode of flickering light superimposed on a dim background light, is shown at the bottom. The dashed line represents 0 intensity. The gray bars indicate the timing of the three acquisition periods, and the arrows point to the corresponding images (see Materials and Methods for details). Müller cell $\mathrm{Ca}^{2+}$ transients are shown in supplemental movie 1 (available at www.jneurosci.org as supplemental material).

results could be reproduced in both preparations. The animals used in this study were treated in accordance with the guidelines of the Institutional Animal Care and Use Committee of the University of Minnesota.

Whole-mount retina. Animals were killed and eyecups were prepared as described previously (Newman and Zahs, 1998). Retinas were gently peeled from the back of the eye so that many retinal pigment epithelium (RPE) cells adhered to the retina. These attached RPE cells permitted the isolated retina to dark adapt and remain responsive to light for several hours, even after exposure to bright illumination. The vitreous humor was removed from retinal pieces by gentle peeling with forceps. Retinas were held in place in a chamber with nylon threads attached to a platinum ring and superfused at $2-3 \mathrm{ml} / \mathrm{min}$ with bicarbonate-buffered Ringer's solution at $24^{\circ} \mathrm{C}$.

Everted eyecup. The back half of the eye was everted over a dome and held in place by an overlying plastic barrier with a hole cut into it, as described previously (Newman and Bartosch, 1999). Excess vitreous humor was then removed by suction. Eyecups were superfused at $2-3 \mathrm{ml} / \mathrm{min}$ with bicarbonate-buffered Ringer's solution at $24^{\circ} \mathrm{C}$ and remained responsive to light for $4-6 \mathrm{~h}$.

Calcium imaging. Retinas were incubated in the $\mathrm{Ca}^{2+}$-indicator dye Fluo-4 AM $(31 \mu \mathrm{g} / \mathrm{ml})$ and pluronic acid $(2.6 \mathrm{mg} / \mathrm{ml})$ for $30 \mathrm{~min}$ at room temperature, as described previously (Newman, 2001b). Whole-mount retinas were incubated after removal of the vitreous humor. Eyecups were incubated after they were mounted in the superfusion chamber, and the vitreous was removed. Dye incubation filled astrocytes and Müller cells efficiently. Ganglion cell somata and axons were labeled to a lesser extent and did not display $\mathrm{Ca}^{2+}$ increases in response to light stimulation. Calcium indicator dye fluorescence was monitored with $488 \mathrm{~nm}$ excitation, a $500 \mathrm{~nm}$ long-pass barrier filter, and confocal microscopy (Odyssey scanner; Noran, Middleton, WI).

Unaveraged confocal images were acquired at $30 \mathrm{~Hz}$ when characterizing the time course of $\mathrm{Ca}^{2+}$ transients generated in Müller cells. Timeaveraged images, which had reduced noise, were acquired at $1.25 \mathrm{~Hz}$ and were used when characterizing the $\mathrm{Ca}^{2+}$ responses evoked by light stimulation. Unless otherwise noted, the focal plane of acquired images was between 0 and $15 \mu \mathrm{m}$ below the vitreal surface of the retina. $\Delta F / F$ scales in the figures represent the magnitude of $\mathrm{Ca}^{2+}$ changes within Müller cells.

Light stimulation. The excitation illumination of the confocal scanner also served as the light stimulus used to evoke neuronal activity. Two stimulation protocols were used. In the flickering light protocol, the illumination was held constant at a low intensity during control periods and alternated between low and high intensities ( $0.8 \mathrm{~s}$ period, $50 \%$ duty cycle) during stimulation periods (Fig. 1, bottom trace). In the light ON protocol, the illumination was stepped from fully off to a constant, me- dium intensity (see Fig. 5C, bottom trace). The relative intensities of the low, medium, and high stimuli were 1:7.1:14.1.

Antidromic activation of ganglion cell axons. Axons were stimulated with $1 \mathrm{~ms},-200$ to $-400 \mu \mathrm{A}$ current pulses passed through a unipolar electrode (Ringer's-filled pipette, $\sim 10$ $\mu \mathrm{m}$ tip diameter). The stimulating electrode was positioned above bundles of axons near the optic disk.

Quantification of $\mathrm{Ca}^{2+}$ transients in Müller cells. Flickering light increased the generation of $\mathrm{Ca}^{2+}$ transients in Müller cells. The frequency of these transients was calculated using imageprocessing functions in MetaMorph (Universal Imaging Corporation, Downingtown, PA). A series of $\mathrm{Ca}^{2+}$ fluorescence images was acquired as a stack and was partitioned into three time periods (Fig. 1, bottom). Images within each period were merged, retaining the maximal value at each pixel. The resulting "maximum" image was divided by the mean of the images in that time period. This normalized image was thresholded, highlighting regions of the image in which $\mathrm{Ca}^{2+}$ had increased transiently sometime during the time period (Fig. 1, red and yellow regions). The same threshold level was used in all experiments and was set so that it was slightly above the $\mathrm{Ca}^{2+}$ fluorescence noise. The integrated morphometry analysis function of MetaMorph was then used to count the number of thresholded regions $>12 \mu \mathrm{m}^{2}$ in area (Fig. 1, yellow regions).

The increase in the number of $\mathrm{Ca}^{2+}$ transients evoked by a flickering light stimulus was calculated as follows:

$\%$ increase in $\mathrm{Ca}^{2+}$ transients $=$

$$
\left(\frac{2 \cdot \text { transients }_{\text {flicker }}}{\text { transients }_{\text {before }}+\text { transients }_{\text {after }}}-1\right) \cdot 100,
$$

where transient $s_{\text {flicker, }}$, transients $_{\text {before, }}$, and transients $s_{\text {after }}$ are the number of transients that occurred during the three measurement periods (during, before, and after presentation) of the flickering light stimulus.

Ganglion cell action potential recording. Action potentials were recorded extracellularly with Ringer's-filled pipettes (2-3 $\mu \mathrm{m}$ tip diameter) positioned within the ganglion cell layer (GCL). Recordings were bandpass filtered $(300-1800 \mathrm{~Hz}$ ) with a MultiClamp $700 \mathrm{~A}$ amplifier (Molecular Devices, Union City, CA).

Solutions and statistics. The bicarbonate-buffered Ringer's solution contained the following (in mM): $111.0 \mathrm{NaCl}, 3.0 \mathrm{KCl}, 2.0 \mathrm{CaCl}_{2}, 1.0 \mathrm{MgSO}_{4}, 0.5$ $\mathrm{NaH}_{2} \mathrm{PO}_{4}, 15.0$ dextrose, and $32 \mathrm{NaHCO}_{3}$. Reagents were purchased from Sigma (St. Louis, MO) except for ( \pm )-1-aminocyclopentane-trans-1,3dicarboxylic acid (trans-ACPD), (RS)-3-(2-carboxypiperazin-4-yl)-propyl1-phosphonic acid (CPP), (RS)-a-cyclopropyl-4-phosphonophenylglycine (CPPG), (RS)-a-ethyl-4-carboxyphenylglycine (E4CPG), L-(+)-2-amino4-phosphonobutyric acid (L-AP-4), 2,3-dioxo-6-nitro-1,2,3,4-tetrahydrobenzo[f] quinoxaline-7-sulfonamide (NBQX), 1-(6-amino-9H-purin-9-yl)-1deoxy- $N$-ethyl- $b$-D-ribofuranuronamide $\quad 5^{\prime}-N$-ethylcarboxamidoadenosine (NECA), $N$-(4-acetylphenyl)-2-[4-(2,3,6,7-tetrahydro-2,6-dioxo-1,3-dipropyl$1 H$-purin-8-yl)phenoxy]acetamide (MRS 1706), 8-cyclopentyl-1,3dipropylxanthine (DPCPX), 4-(2-[7-amino-2-(2-furyl)[1,2,4] triazolo[2,3a] $[1,3,5]$ triazin-5-ylamino] ethyl)phenol (ZM 241385), and scopolamine, which were purchased from Tocris Cookson (Ellisville, MO). All drugs were added directly to the superfusate solutions.

Numerical values are given as mean \pm SEM with $n$ in parentheses, except when otherwise noted. Statistical significance was determined by the single-tailed Student's $t$ test.

\section{Results}

Two types of macroglial cells are present in the mammalian retina: astrocytes and Müller cells (Newman, 2001a). Astrocytes are 

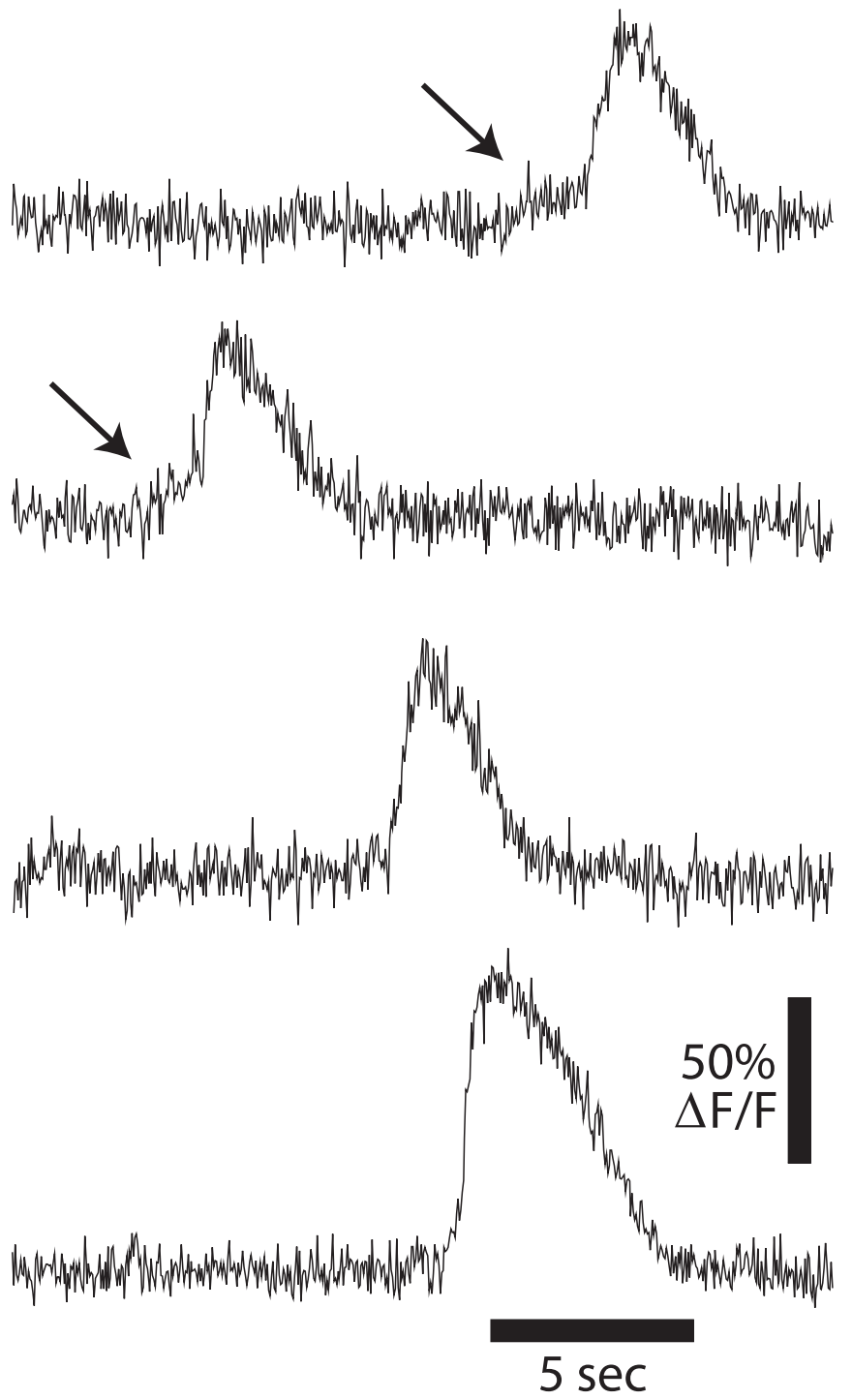

Figure 2. Calcium transients in individual Müller cells in retinas under constant illumination. In some Müller cells, $\mathrm{Ca}^{2+}$ rose rapidly from a flat baseline. In others, the rapid rise in $\mathrm{Ca}^{2+}$ was preceded by a smaller, slow $\mathrm{Ca}^{2+}$ increase (arrows). The four traces were obtained in different trials. Calcium fluorescence images were acquired at $30 \mathrm{~Hz}$.

confined mainly to the nerve fiber layer at the inner (vitreal) border of the retina. Müller cells, the principal retinal glial cells, extend from the inner border of the retina to the photoreceptor layer in the outer retina.

\section{Calcium transients in Müller cells}

Transient increases in $\mathrm{Ca}^{2+}$ were observed in Müller cells in retinas under constant illumination (Fig. 2) (supplemental movie 1, available at www.jneurosci.org as supplemental material). The time course of the $\mathrm{Ca}^{2+}$ transients varied in different cells. For some transients, $\mathrm{Ca}^{2+}$ rose rapidly from a flat baseline. In others, the rapid rise of $\mathrm{Ca}^{2+}$ was preceded by a smaller, slow $\mathrm{Ca}^{2+}$ increase (Fig. 2, arrows), suggesting that a small $\mathrm{Ca}^{2+}$ increase can trigger a larger $\mathrm{Ca}^{2+}$ transient, perhaps through activation of $\mathrm{Ca}^{2+}$-induced $\mathrm{Ca}^{2+}$ release.

The duration of the $\mathrm{Ca}^{2+}$ transients ranged from 2.5 to $6 \mathrm{~s}$ and averaged $3.84 \pm 0.82 \mathrm{~s}$ (mean $\pm \mathrm{SD} ; n=37$ ). The transients had a mean rise time of $0.89 \pm 0.39 \mathrm{~s}$ (time from 10 to $90 \%$ of peak amplitude) and a decay time of $2.01 \pm 0.77 \mathrm{~s}$ (time from 90 to
$10 \%$ of peak amplitude). The amplitude of the transients ranged from 14 to $140 \% \Delta F / F$ and averaged $49 \pm 18 \% \Delta F / F$.

The frequency of $\mathrm{Ca}^{2+}$ transient generation varied in different preparations and depended on the age of the preparation, decreasing as preparations aged. Calcium transients occurred at a rate of 1-15 transients/Müller cell/1000 s and averaged 4.6 transients/cell/1000 s. During single trials lasting $56 \mathrm{~s}, \mathrm{Ca}^{2+}$ transients were generated in $9.5 \pm 2.1 \%(n=12)$ of Müller cells imaged.

During a $\mathrm{Ca}^{2+}$ transient, $\mathrm{Ca}^{2+}$ increases were observed in Müller cell processes within the ganglion cell layer and inner plexiform layer (IPL) and in cell endfeet at the vitreal surface of the retina. Calcium increases were not seen in cell somata or in processes in deeper retinal layers. The $\mathrm{Ca}^{2+}$ transients occurred in individual cells and did not propagate from one Müller cell to another. Calcium transients were not seen in astrocytes.

\section{Light-evoked increase in $\mathrm{Ca}^{2+}$ transients}

The frequency of Müller cell $\mathrm{Ca}^{2+}$ transients increased when the retina was stimulated with a flickering light (Figs. 1, 3A), which is a particularly effective stimulus for activating neurons in the inner retina (Miller, 2001; Wassle, 2004). In the experiment illustrated in Figure 1, 33 transients occurred during the control period before stimulation (Fig. $1 A$ ), 55 transients occurred while the retina was stimulated with a flickering light (Fig. $1 B$ ), and 31 transients occurred in a second control period after cessation of the light stimulus (Fig. 1C). On average, the generation of $\mathrm{Ca}^{2+}$ transients increased $28.1 \pm 5.4 \%(n=10 ; p<0.0005)$ when the retina was stimulated by flickering light. Light-evoked $\mathrm{Ca}^{2+}$ increases were not observed in astrocytes.

The time course of the light-evoked Müller cell $\mathrm{Ca}^{2+}$ response was determined by averaging $\mathrm{Ca}^{2+}$ responses from 84 experiments. Calcium signals from all Müller cells within the field of view in each experiment ( $\sim 260$ cells) were included in the average. The mean light-evoked $\mathrm{Ca}^{2+}$ increase is illustrated in Figure $3 \mathrm{~B}$ and shows that $\mathrm{Ca}^{2+}$ transients are most likely to be generated in Müller cells during the first $2 \mathrm{~s}$ after the onset of a flickering light. However, the rate of $\mathrm{Ca}^{2+}$ transient generation remains raised for the duration of the flickering stimulus. The rise time, decay time, and amplitude of the $\mathrm{Ca}^{2+}$ transients evoked by a light stimulus did not differ significantly from $\mathrm{Ca}^{2+}$ transients observed under constant illumination.

\section{Pharmacology of $\mathrm{Ca}^{2+}$ transient increase}

Agonists

ATP has been shown previously to be an effective glial cell stimulus, evoking large $\mathrm{Ca}^{2+}$ increases in Müller cells (Newman and Zahs, 1997; Newman, 2001b; Reifel Saltzberg et al., 2003) as well as astrocytes (Finkbeiner, 1993; Bowser and Khakh, 2004). A low concentration of ATP proved to be effective in increasing the rate of $\mathrm{Ca}^{2+}$ transients in Müller cells. Under steady illumination, 0.1 $\mu \mathrm{M}$ ATP increased the occurrence of $\mathrm{Ca}^{2+}$ transients $17.9 \pm$ $11.8 \%(n=10)$ (Fig. $4 A$ ). This is nearly as large as the $28 \%$ increase seen in response to a flickering light. Both 0.3 and $1.0 \mu \mathrm{M}$ ATP increased the occurrence of $\mathrm{Ca}^{2+}$ transients to a greater extent, $56.5 \pm 19.6 \%(n=16)$ and $384 \pm 58 \%(n=4)$, respectively. Application of ATP increased $\mathrm{Ca}^{2+}$ in astrocytes as well as Müller cells. In astrocytes, however, sustained $\mathrm{Ca}^{2+}$ increases, rather than transient responses, were observed.

The mean amplitude of Müller cell $\mathrm{Ca}^{2+}$ transients evoked by ATP $(1 \mu \mathrm{M})$ was $65 \pm 32 \Delta F / F$, somewhat larger than the amplitude of transients measured in the absence of ATP $(p<0.005)$. However, the rise and the decay times of ATP-evoked transients 

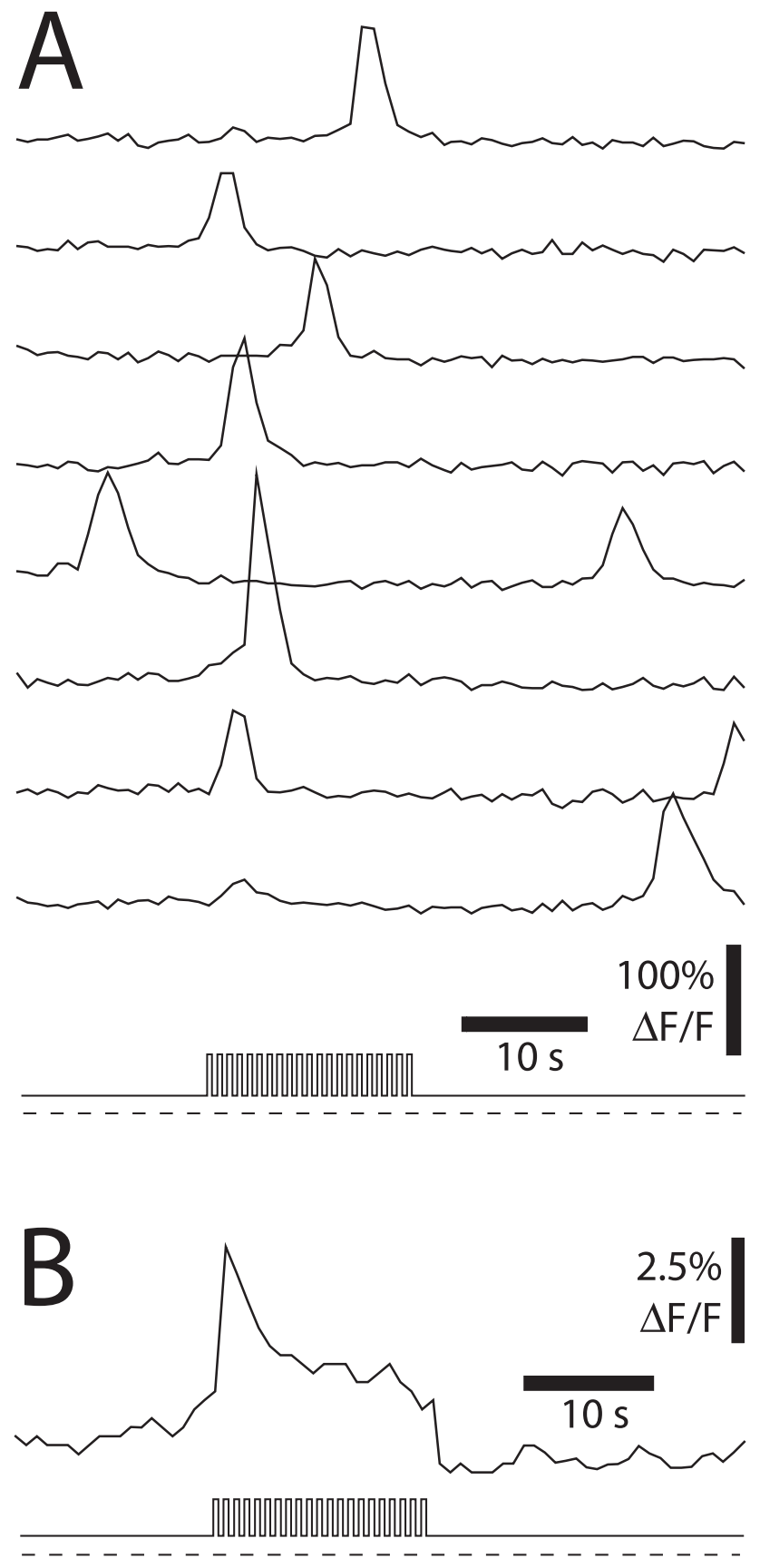

Figure 3. Light-evoked $\mathrm{Ca}^{2+}$ increases in Müller cells. $\boldsymbol{A}$, Calcium fluorescence measured simultaneously in eight Müller cells. Calcium transients are more likely to be generated during the flickering light stimulus. $\boldsymbol{B}$, Mean $\mathrm{Ca}^{2+}$ fluorescence increase evoked by a flickering light. The response represents transient $\mathrm{Ca}^{2+}$ increases averaged over 84 trials. The $\mathrm{Ca}^{2+}$ fluorescence from $\sim 260$ Müller cells was monitored in each trial. A linear downward slope of the trace, caused by dye bleaching, has been subtracted. The light stimulus is shown at the bottom in both $A$ and $B$.

did not differ significantly from those measured in control preparations.

\section{Antagonists}

The effectiveness of ATP in increasing the occurrence of Müller cell $\mathrm{Ca}^{2+}$ transients suggests that ATP, or a related agonist, might be responsible for neuron-to-glia signaling and for eliciting lightevoked increases in Müller cell $\mathrm{Ca}^{2+}$ transients. This was tested by blocking ATP signaling with the purinergic antagonist suramin. Suramin proved effective in reducing the light-evoked
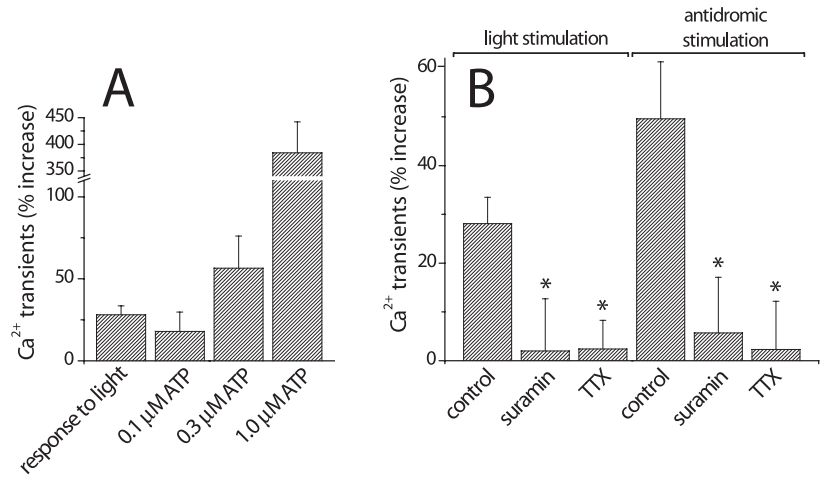

Figure 4. Effect of agonists and antagonists on $\mathrm{Ca}^{2+}$ transients in Müller cells. $A$, Both a flickering light stimulus and addition of ATP to the superfusate evoke increases in the generation of $\mathrm{Ca}^{2+}$ transients. $\boldsymbol{B}, \mathrm{A}$ flickering light evokes an increase in the generation of $\mathrm{Ca}^{2+}$ transients (light stimulation; control). The response is blocked by $100 \mu \mathrm{m}$ suramin and $200 \mathrm{~nm}$ TTX. Antidromic activation of ganglion cell axons evokes an increase in the occurrence of $\mathrm{Ca}^{2+}$ transients (antidromic stimulation; control). This response is also blocked by $30 \mu \mathrm{m}$ suramin and $200 \mathrm{~nm}$ TTX. Asterisks indicate a significant difference from controls $\left({ }^{*} p<0.05\right)$. The flickering light protocol used in $\boldsymbol{A}$ and $\boldsymbol{B}$ is illustrated in Figure 1.

Müller cell response. Suramin $(100 \mu \mathrm{M})$ diminished the lightevoked increase in $\mathrm{Ca}^{2+}$ transients to $2.0 \pm 10.7 \%(n=11)$ of control (Fig. 4B). Additional pharmacological tests, described below, support the conclusion that neuron-to-glia signaling is mediated by ATP.

The effect of suramin was not caused by a reduction of lightevoked neuronal activity. In seven of nine ganglion cells monitored, light-evoked spiking was either unchanged or increased with the addition of $100 \mu \mathrm{M}$ suramin, whereas in the remaining two cells, suramin reduced spiking only slightly. Suramin also increased the rate of spontaneous spiking in three of the nine ganglion cells.

The $\mathrm{Na}^{+}$channel blocker tetrodotoxin (TTX) was also effective in blocking the light-evoked Müller cell response. TTX (200 $\mathrm{nM})$ reduced the light-evoked increase in the generation of $\mathrm{Ca}^{2+}$ transients to $2.4 \pm 5.9 \%(n=12)$ of control (Fig. $4 B)$.

\section{Calcium increases evoked by antidromic activation of} ganglion cells

TTX block of the light-evoked increase in Müller cell $\mathrm{Ca}^{2+}$ transients suggests that amacrine cells and/or ganglion cells, the only neurons in the retina that generate action potentials, are responsible for neuron-to-glia signaling. The involvement of ganglion cells in generating the Müller cell response was tested by antidromically stimulating these cells. Bundles of ganglion cell axons were stimulated for $16 \mathrm{~s}$ at $50 \mathrm{~Hz}$. Ganglion cell activation produced a $49.6 \pm 11.7 \%(n=7)$ increase in the generation of $\mathrm{Ca}^{2+}$ transients in Müller cells, greater than the increase evoked by a flickering light (Fig. $4 \mathrm{~B}$ ). The increased $\mathrm{Ca}^{2+}$ signaling produced by antidromic activation of ganglion cells was reduced to $5.7 \pm$ $11.4 \%(n=15)$ by $30 \mu \mathrm{M}$ suramin, suggesting again that neuron to glia signaling is mediated by ATP release. The increased response produced by antidromic activation was reduced to $2.3 \pm$ 9.9\% $(n=7)$ by TTX, demonstrating that the increased Müller cell $\mathrm{Ca}^{2+}$ signaling was not attributable to direct stimulation of the glial cells. Antidromic stimulation did not evoke $\mathrm{Ca}^{2+}$ increases in astrocytes.

\section{Adenosine potentiation of light-evoked $\mathrm{Ca}^{2+}$ increases}

Adenosine has been reported previously to potentiate ATPevoked $\mathrm{Ca}^{2+}$ increases in cultured astrocytes by acting synergis- 

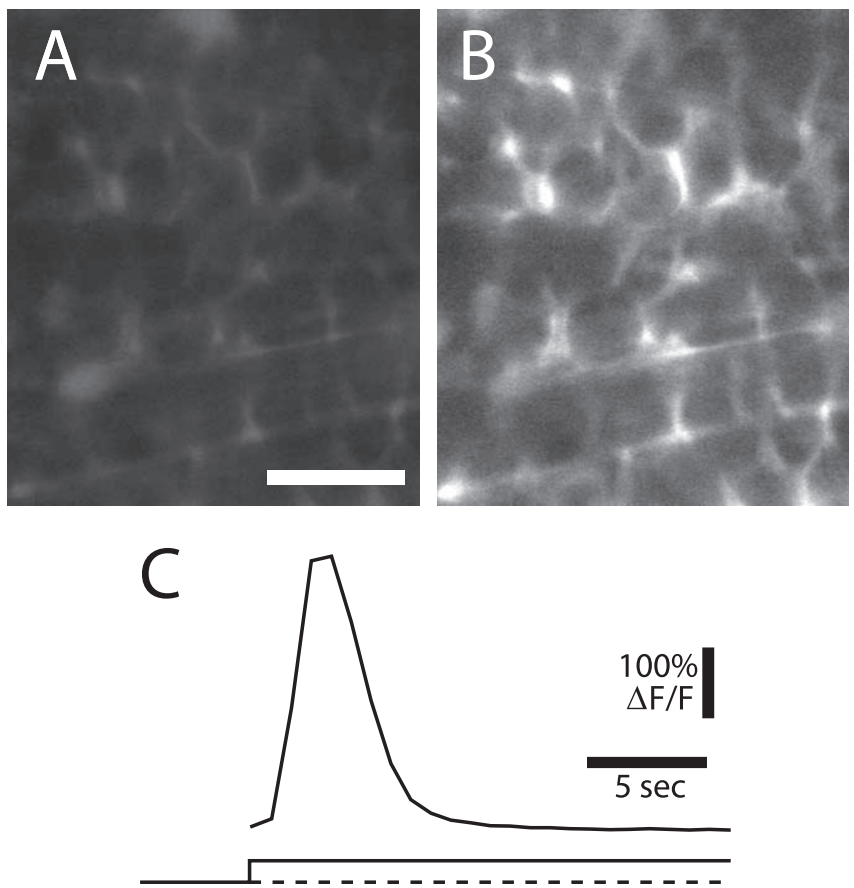

Figure 5. Adenosine potentiates the light-evoked Müller cell $\mathrm{Ca}^{2+}$ increase (100 $\mu \mathrm{m}$ adenosine in superfusate). $\boldsymbol{A}, \boldsymbol{B}, \mathrm{Ca}^{2+}$ fluorescence images within the ganglion cell layer. During the first $0.8 \mathrm{~s}$ after light $\mathrm{ON}(\boldsymbol{A}), \mathrm{Ca}^{2+}$ remains low within Müller cells. At $3.1 \mathrm{~s}$ after light $\mathrm{ON}(\boldsymbol{B})$, Müller cell $\mathrm{Ca}^{2+}$ has risen substantially. Müller cell processes surrounding ganglion cell somata (dark circles) are visible. Scale bar, $20 \mu \mathrm{m}$. C, Time course of $\mathrm{Ca}^{2+}$ rise in Müller cells for the experiment illustrated in $\boldsymbol{A}$ and $\boldsymbol{B}$. The light stimulus is shown at the bottom. The dashed line represents 0 intensity. This trial is shown in supplemental movie 2 (available at www.jneurosci.org as supplemental material).

tically with ATP in the glial cells (Alloisio et al., 2004; Nishizaki, 2004). Adenosine agonists proved effective in potentiating lightevoked $\mathrm{Ca}^{2+}$ increases in Müller cells as well. In the presence of $100 \mu \mathrm{M}$ adenosine or $2 \mu \mathrm{M}$ NECA (a nonselective adenosine agonist), a light stimulus evoked large $\mathrm{Ca}^{2+}$ increases in Müller cells (Fig. 5) (supplemental movie 2, available at www.jneurosci.org as supplemental material). Light $\mathrm{ON}$, rather than a flickering light, was sufficient to produce the response. Müller cell $\mathrm{Ca}^{2+}$ levels remained low for 1-2 s after light ON (Fig. 5A). During the next several seconds, however, $\mathrm{Ca}^{2+}$ levels increased dramatically (Fig. $5 B$ ), peaking at $\sim 3 \mathrm{~s}$ after light $\mathrm{ON}$ (Fig. $5 C$ ). Light-evoked $\mathrm{Ca}^{2+}$ increases were not observed in astrocytes in the presence of adenosine agonists.

Adenosine potentiation of light-evoked Müller cell $\mathrm{Ca}^{2+}$ responses was not a result of an adenosine-mediated increase in neuronal activity. In the presence of $100 \mu \mathrm{M}$ adenosine, lightevoked ganglion cell spike activity was reduced. Of the six cells monitored, all six showed a decrease in light-evoked spiking in the presence of adenosine, and five showed a reduction in spontaneous activity. Similar results have been reported previously (Blazynski and Perez, 1991). This finding indicates that adenosine is acting synergistically with ATP at retinal glial cells, rather than acting by potentiating neuronal activity.

Adenosine agonists most likely potentiate $\mathrm{Ca}^{2+}$ responses by stimulating Müller cell adenosine receptors. The effect of adenosine receptor antagonists on the adenosine-potentiated $\mathrm{Ca}^{2+}$ response was assessed to determine the receptor type mediating the potentiation. In the presence of $2 \mu \mathrm{M}$ NECA, the $A_{2 B}$ receptor antagonist MRS $1706(1 \mu \mathrm{M})$ reduced the light-evoked Müller cell response to $3.6 \pm 1.2 \%(n=6)$ of control. The $\mathrm{A}_{1}$ and $\mathrm{A}_{2 \mathrm{~A}}$
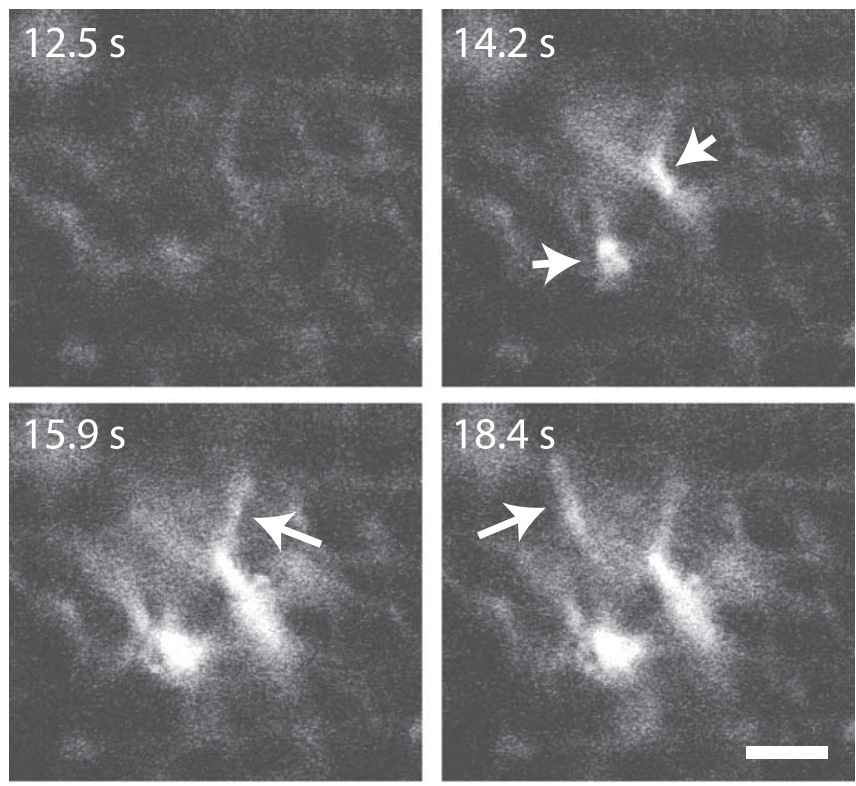

Figure 6. Light-evoked, propagated $\mathrm{Ca}^{2+}$ wave in Müller cells (100 $\mu$ madenosine in superfusate). Calcium florescence images in the ganglion cell layer are shown. Within the first seconds after light $\mathrm{ON}$, there is a large $\mathrm{Ca}^{2+}$ increase in all Müller cells (data not shown). By $12.5 \mathrm{~s}$ after light $0 \mathrm{~N}$, this $\mathrm{Ca}^{2+}$ increase has decayed (12.5 s). At $14.2 \mathrm{~s}$, a secondary rise in $\mathrm{Ca}^{2+}$ occurs in two Müller cells (short arrows). This $\mathrm{Ca}^{2+}$ increase propagates into adjacent Müller cells at 15.9 and $18.4 \mathrm{~s}$ (long arrows). Numbers indicate elapsed time after light $0 \mathrm{~N}$. Scale bar, $10 \mu \mathrm{m}$. This trial is shown in supplemental movie 3 (available at www.jneurosci.org as supplemental material).

antagonists DPCPX and ZM 241385 were less effective in reducing the response. DPCPX $(10 \mathrm{nM})$ reduced the response to $18.3 \pm$ $2.6 \%(n=5)$, whereas ZM $241385(1 \mu \mathrm{M})$ reduced the response to $21.5 \pm 3.8 \%(n=5)$. The results are somewhat difficult to interpret, because the antagonists are not completely selective for specific receptor subtypes. However, the results suggest that adenosine potentiation of Müller cell $\mathrm{Ca}^{2+}$ responses is mediated primarily by $\mathrm{A}_{2 \mathrm{~B}}$ receptors, in agreement with previous findings (Alloisio et al., 2004).

The light-evoked, adenosine-potentiated Müller cell response was eliminated by the addition of a combination of $100 \mu \mathrm{M}$ L-AP-4 and $10 \mu \mathrm{M}$ NBQX, which block synaptic transmission from photoreceptors to $\mathrm{ON}$ and OFF bipolar cells, respectively. The addition of L-AP-4/NBQX reduced the Müller cell response to $0.9 \pm 0.2 \%(n=2)$ of control. This result demonstrates that the Müller cell response is driven by light-evoked neuronal activity and is not attributable to an inherent light sensitivity of the glial cells.

\section{Propagated $\mathrm{Ca}^{2+}$ waves}

In the presence of an adenosine agonist, light stimulation sometimes evoked a delayed $\mathrm{Ca}^{2+}$ response in Müller cells after the large, short-latency response (Fig. 6) (supplemental movie 3, available at www.jneurosci.org as supplemental material). This delayed response had a latency of 7.5-14 s (mean, 11.4 s) and was observed infrequently ( 6 of 63 experiments). The remarkable feature of this response was that it originated in only one or two Müller cells and then, during the next several seconds, propagated into neighboring Müller cells. Propagated waves were never observed in the absence of a light stimulus or without adenosine potentiation. 

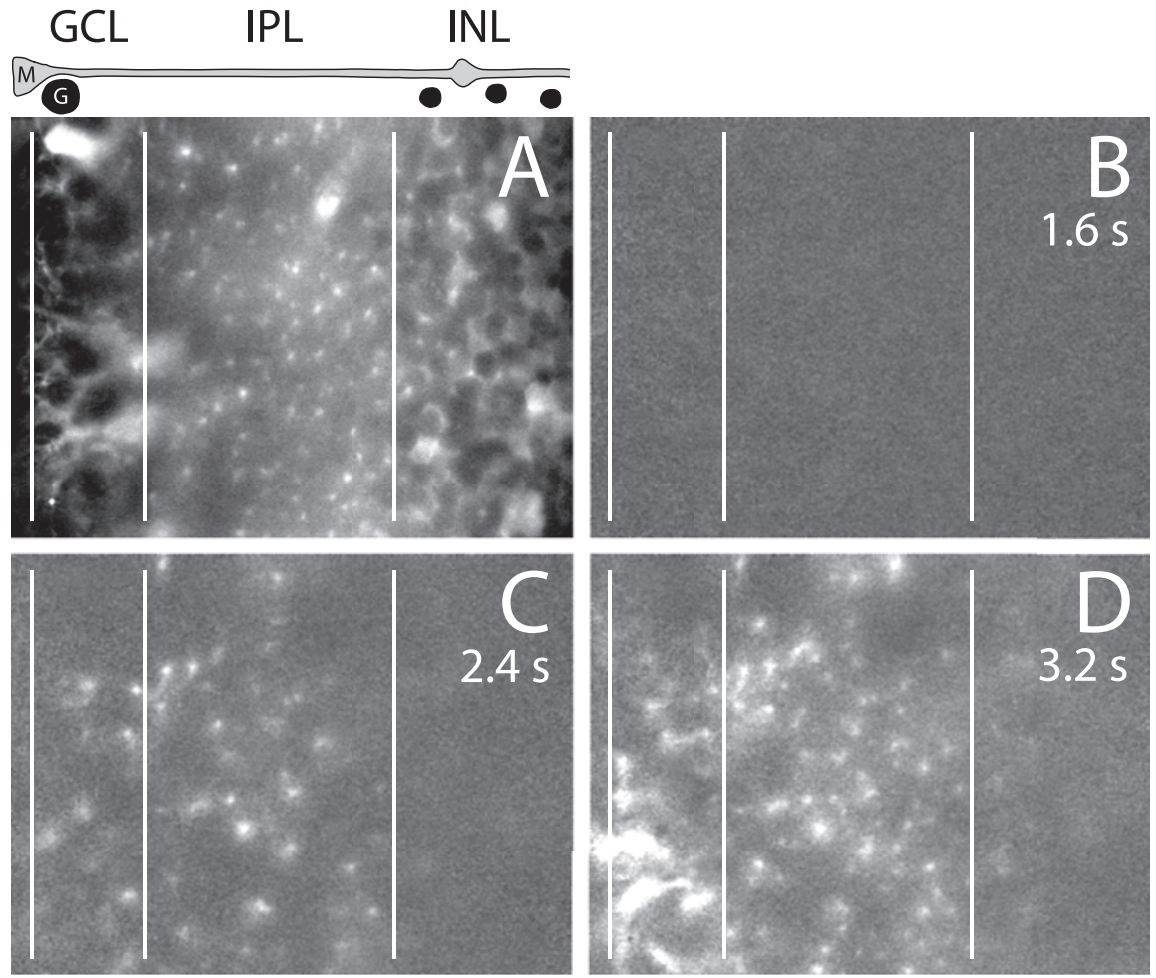

Figure 7. Light-evoked Müller cell $\mathrm{Ca}^{2+}$ increases within different retinal layers (5 $\mu \mathrm{m}$ NECA in superfusate). The images are from an oblique optical section through an everted eyecup and show retinal layers within the inner half of the retina. The vertical lines indicate boundaries between retinal layers. INL, Inner nuclear layer. The drawing above $\boldsymbol{A}$ shows the location of a Müller cell $(\mathrm{M})$, a ganglion cell soma (G), and neuronal somata within the INL (unlabeled). $\boldsymbol{A}, \mathrm{Ca}^{2+}$ fluorescence image in the unstimulated retina. Müller cells are selectively labeled. Müller cell processes surrounding ganglion cell somata in the $\mathrm{GCL}$, Müller cell stalk processes in the IPL, and Müller cell processes surrounding neuronal somata in the INL are shown. $\boldsymbol{B}-\boldsymbol{D}, \mathrm{Ca}^{2+}$ fluorescence ratio images showing the change in $\mathrm{Ca}^{2+}$ after light $0 \mathrm{~N}$. At $1.6 \mathrm{~s}$ after light $0 \mathrm{~N}(\boldsymbol{B})$, no increase in $\mathrm{Ca}^{2+}$ is seen. At $2.4 \mathrm{~s}(\boldsymbol{C}), \mathrm{Ca}^{2+}$ rises in Müller cell processes within the inner and middle IPL and, to a lesser extent, in the GCL. At $3.2 s(\boldsymbol{D})$, Müller cell $\mathrm{Ca}^{2+}$ increases have spread throughout the $\mathrm{GCL}$ and into Müller cell endfeet at the inner retinal surface (far left). Müller cell $\mathrm{Ca}^{2+}{ }^{2+}$ increases also spread throughout the IPL and into the inner portion of the INL.

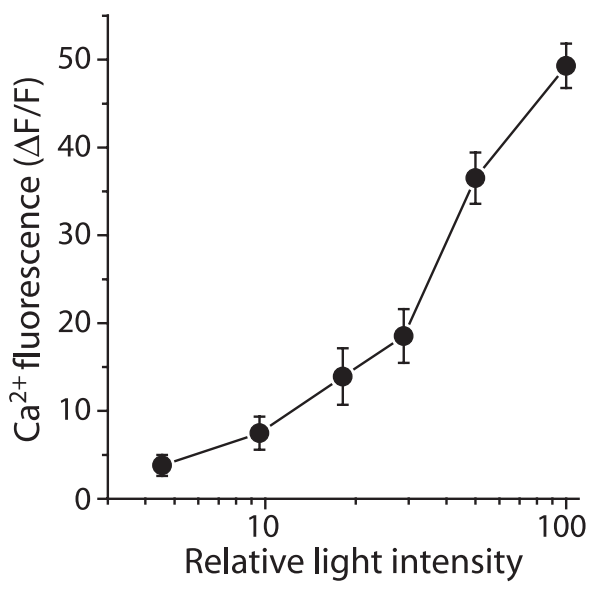

Figure 8. Intensity-response relationship of the light-evoked $\mathrm{Ca}^{2+}$ increase in Müller cells. The peak $\mathrm{Ca}^{2+}$ fluorescence amplitude is plotted as a function of the intensity of the light stimulus ( $2 \mu \mathrm{M}$ NECA in superfusate). Mean amplitude \pm SEM is shown; $n=7$.

\section{Retinal location of $\mathrm{Ca}^{2+}$ increases}

Light-evoked, adenosine-potentiated Müller cell $\mathrm{Ca}^{2+}$ responses were monitored in different retinal layers. The response originated in Müller cell processes within the inner and middle regions of the IPL. It then spread distally into processes within the outer IPL and proximally into processes in the GCL and into cell endfeet at the inner surface of the retina. Light-evoked $\mathrm{Ca}^{2+}$ increases were never observed in Müller cell somata in the inner nuclear layer.

This pattern of Müller cell $\mathrm{Ca}^{2+}$ responses was monitored in individual trials by imaging a region of the everted eyecup, where many retinal layers could be visualized in a single image (Fig. 7A). Oblique confocal sections were made by focusing on a sloping portion of the eyecup. In the first $1-2 \mathrm{~s}$ after light $\mathrm{ON}$, no $\mathrm{Ca}^{2+}$ increases were seen (Fig. 7B). At 2.4 s, however, $\mathrm{Ca}^{2+}$ increases were observed in the inner and middle regions of the IPL and in the GCL (Fig. 7C). At $3.2 \mathrm{~s}, \mathrm{Ca}^{2+}$ increases had spread proximally into Müller cell endfeet at the surface of the retina and distally into the INL (Fig. 7D). It is not clear whether the spread of the $\mathrm{Ca}^{2+}$ response within Müller cells represents an intracellular propagated wave or simply a sequential activation of different Müller cell regions by external stimuli (Keirstead and Miller, 1995; Reifel Saltzberg et al., 2003).

Intensity-response relationship

The magnitude of the Müller cell $\mathrm{Ca}^{2+}$ response in the presence of adenosine agonists varied as a function of the intensity of the light stimulus. In the presence of $2 \mu \mathrm{M}$ NECA, larger light-evoked $\mathrm{Ca}^{2+}$ responses were observed as the intensity of the stimulus increased. Over the range of intensities tested, the log intensity versus $\mathrm{Ca}^{2+}$ response relationship had a sigmoidal form (Fig. 8), as does the log intensity versus response relationship of retinal neurons.

\section{Pharmacology of adenosine-potentiated $\mathrm{Ca}^{2+}$ increases Agonists}

ATP was effective in evoking large $\mathrm{Ca}^{2+}$ increases in Müller cells in the presence of adenosine or NECA. The addition of $0.1,0.3$, and $1.0 \mu \mathrm{M}$ ATP evoked $\mathrm{Ca}^{2+}$ increases of $7.0 \pm 3.9 \%(n=5)$, $39.8 \pm 7.7 \%(n=5)$, and $157.3 \pm 18.4 \%(n=6)$, the magnitude of the $\mathrm{Ca}^{2+}$ increase produced by a light stimulus (Fig. $9 A$ ). In contrast, metabotropic glutamate receptors, which mediate neuron-to-glia signaling in brain slices (Schipke and Kettenmann, 2004), play little role in neuron-glia signaling in the retina. The group I/II metabotropic glutamate agonist trans-ACPD was ineffective in evoking a Müller cell $\mathrm{Ca}^{2+}$ response. The addition of 200 and $600 \mu \mathrm{M}$ trans-ACPD evoked $\mathrm{Ca}^{2+}$ increases only $1.7 \pm 1.1 \%(n=5)$ and $2.7 \pm 1.4 \%(n=6)$, the magnitude of the $\mathrm{Ca}^{2+}$ increase produced by a light stimulus.

\section{Antagonists}

An ATP-mediated neuron-to-glia signaling mechanism is supported by experiments using receptor antagonists (Fig. 9B). The purinergic antagonist suramin $(30 \mu \mathrm{M})$ reduced the light-evoked response to $12.6 \pm 4.6 \%(n=10)$ of control, whereas apyrase $(100 \mathrm{U} / \mathrm{ml})$, which selectively hydrolyzes ATP, reduced the response to $9.6 \pm 5.4 \%(n=4)$ of control. TTX reduced the lightevoked Müller cell response to $36.3 \pm 6.1 \%(n=13)$ of control.

Neuronal release of glutamate, GABA, and acetylcholine has 
been shown to elicit glial $\mathrm{Ca}^{2+}$ increases in brain slices by activating metabotropic glial receptors (Schipke and Kettenmann, 2004). However, these transmitters do not contribute substantially to neuron-glia signaling in the retina. Antagonists to these transmitters were mainly ineffective in blocking the light-evoked Müller cell $\mathrm{Ca}^{2+}$ response (Fig. 9B). In the presence of the NMDA antagonist CPP $(10 \mu \mathrm{M})$, the group I/II metabotropic glutamate antagonist E4CPG $(200 \mu \mathrm{M})$ and E4CPG plus the group III metabotropic glutamate antagonist CPPG $(2 \mu \mathrm{M})$, light-evoked responses were $101 \pm 14 \%(n=4), 77 \pm$ $10 \%(n=6)$, and $61 \pm 9 \%(n=5)$ of control, respectively. GABA and ACh antagonists were similarly ineffective. In the presence of the $\mathrm{GABA}_{\mathrm{B}}$ antagonist saclofen $(200 \mu \mathrm{M})$ and the muscarinic antagonist scopolamine $(10 \mu \mathrm{M})$, light-evoked responses were $93 \pm 1 \%(n=4)$ and $102 \pm$ $7 \%(n=6)$ of control, respectively.

The role of ganglion cells in generating the adenosinepotentiated Müller cell response was tested by stimulating ganglion cells. Antidromic activation of ganglion cell axons resulted in small increases in Müller cell $\mathrm{Ca}^{2+}$ in the presence of $2 \mu \mathrm{M}$ NECA. Ganglion cell activation evoked $\mathrm{Ca}^{2+}$ responses that were $29.0 \pm 4.3 \%(n=7)$, the magnitude of responses produced by light stimulation. The addition of $100 \mu \mathrm{M}$ suramin reduced these responses to $3.9 \pm 3.9 \%(n=3)$ of control. Responses were completely blocked by $200 \mathrm{~nm}$ TTX (response amplitude, $0.3 \pm$ $0.3 \%$ of control; $n=4$ ). In some preparations, antidromic stimulation failed to evoke Müller cell $\mathrm{Ca}^{2+}$ increases.

Cyclopiazonic acid $(30 \mu \mathrm{M})$, which depletes internal $\mathrm{Ca}^{2+}$ stores, nearly abolished the light-evoked, NECA-potentiated Müller cell $\mathrm{Ca}^{2+}$ response (Fig. $\left.9 B\right)(2.7 \pm 0.9 \%$ of control; $n=$ 4). Cyclopiazonic acid also abolished Müller cell $\mathrm{Ca}^{2+}$ transients in preparations not potentiated by an adenosine agonist (1.0 \pm $1.0 \%$ of control; $n=3$ ). Calcium transients observed under both constant and flickering illumination were blocked. These results suggest that $\mathrm{Ca}^{2+}$ responses in Müller cells are generated by $\mathrm{Ca}^{2+}$ release from internal stores.

\section{Müller cell depolarization}

Light-evoked neuronal activity elicits slow depolarizations in Müller cells (Karwoski and Proenza, 1977; Karwoski and Proenza, 1980). These depolarizations are evoked by $\mathrm{K}^{+}$release from neurons and are small in amplitude, $\sim 0.5-2 \mathrm{mV}$. Experiments were conducted to determine whether $\mathrm{K}^{+}$-mediated depolarization contributes to the light-evoked $\mathrm{Ca}^{2+}$ response observed in Müller cells. Müller cell depolarization was blocked by addition of $\mathrm{Ba}^{2+}$, which, at low concentration, selectively blocks inwardly rectifying $\mathrm{K}^{+}$channels. In the presence of $100 \mu \mathrm{M} \mathrm{Ba}^{2+}$, which blocks $>90 \%$ of Müller cell $\mathrm{K}^{+}$conductance (Newman, 1989, 1993), the amplitude of NECA-potentiated, light-evoked Müller cell $\mathrm{Ca}^{2+}$ responses was $97.0 \pm 3.3 \%(n=6)$ of control, not significantly different from responses in the absence of $\mathrm{Ba}^{2+}$. The results demonstrate that $\mathrm{K}^{+}$-mediated depolarization does not contribute significantly to the generation of Müller cell $\mathrm{Ca}^{2+}$ responses.

\section{Discussion}

Light-evoked glial $\mathrm{Ca}^{2+}$ increases

The results of this study demonstrate that a natural stimulus, light flashes, can evoke $\mathrm{Ca}^{2+}$ increases in glial cells. A flickering light evokes significant increases in the generation of $\mathrm{Ca}^{2+}$ transients in Müller cells. In the presence of adenosine, a single light flash can evoke substantially larger increases in Müller cell $\mathrm{Ca}^{2+}$. These results represent the first demonstration that a natural stimulus can evoke $\mathrm{Ca}^{2+}$ increases in CNS glial cells.

Under constant illumination, Müller cell $\mathrm{Ca}^{2+}$ transients occur at an average rate of 4.6 transients/cell/1000 s. Similar $\mathrm{Ca}^{2+}$ transients have been observed in astrocytes in unstimulated brain slices (Parri et al., 2001; Aguado et al., 2002; Nett et al., 2002) as well as in the unstimulated cortex in vivo (Hirase et al., 2004). Astrocyte $\mathrm{Ca}^{2+}$ transients in vivo occur at an average rate of 0.22 transients/cell/1000 s (Hirase et al., 2004), a somewhat lower frequency than that observed in Müller cells. Calcium transients in Müller cells and astrocytes appear to be a naturally occurring glial signal.

In control superfusate as well as in the presence of adenosine, light-evoked $\mathrm{Ca}^{2+}$ increases were observed in Müller cells but not in astrocytes. This contrasts with findings in brain slices, in which neuron-evoked $\mathrm{Ca}^{2+}$ increases are observed in astrocytes (Schipke and Kettenmann, 2004). However, the present results are not surprising, because Müller cells function as astrocytes in the retina (Newman and Reichenbach, 1996). Müller cells surround neuronal somata, dendrites, and synapses in the retina. In contrast, astrocytes primarily contact ganglion cell axons and are not associated with retinal synapses. They are too distant from the synaptic layers of the retina to respond to light-evoked release of neurotransmitters.

Calcium imaging in different retinal layers demonstrates that neuron-to-glia signaling occurs primarily within the inner plexiform layer, the principal synaptic layer of the retina. In response to light $\mathrm{ON}, \mathrm{Ca}^{2+}$ increases begin within the inner and middle portions of the inner plexiform layer, where neurons responding to light $\mathrm{ON}$ are located.

\section{ATP and neuron-to-glia signaling}

The results suggest that neuron-to-glia signaling in the retina is mediated by ATP release from neurons and activation of glial 
purinergic receptors. The addition of ATP in both control and adenosine-potentiated preparations evoked Müller cell $\mathrm{Ca}^{2+}$ increases similar to those elicited by light stimulation. In addition, the purinergic antagonist suramin effectively blocked lightevoked glial $\mathrm{Ca}^{2+}$ increases and apyrase, an ectoenzyme that selectively hydrolyzes ATP, blocked adenosine-potentiated responses.

In contrast, glutamate does not play a significant role in neuron-glial signaling in the retina. In the brain, glutamatergic signaling onto glia is mediated primarily by glial mGluRs (Schipke and Kettenmann, 2004). In the present study, mGluR agonists did not raise glial $\mathrm{Ca}^{2+}$, and mGluR antagonists had little effect on light-evoked glial responses.

Light-evoked glial $\mathrm{Ca}^{2+}$ increases were substantially reduced by TTX, suggesting that neuron-to-glia signaling is mediated by amacrine or ganglion cells, the two types of retinal neurons that generate action potentials. Amacrine cells are believed to release ATP (Santos et al., 1999). The cholinergic starburst amacrine is a likely candidate to mediate neuron-glia signaling, because it may corelease ATP along with acetylcholine (Neal and Cunningham, 1994). [TTX may also act on retinal bipolar cells, because they express TTX-sensitive $\mathrm{Na}^{+}$channels (Zenisek et al., 2001).]

In addition to amacrine cells, ganglion cells may also release ATP and signal to glia. Antidromic activation of ganglion cells results in Müller cell $\mathrm{Ca}^{2+}$ increases, a response blocked by suramin. Although ganglion cell axons do not synapse within the retina, nonsynaptic release of ATP from neurons has been described previously (Fields and Stevens, 2000; Stevens and Fields, 2000).

However, the antidromic stimulation experiments can be interpreted in other ways. A small fraction of mammalian optic nerve axons are efferent fibers that synapse within the retina (Mikkelsen, 1992) and could activate Müller cells. Antidromic activation of ganglion cells could also result in Müller cell stimulation by depolarizing amacrine cells, because gap junctional coupling between ganglion cells and amacrine cells has been reported previously (Xin and Bloomfield, 1997; Wright and Vaney, 2004).

The results of this study provide strong, but not conclusive, evidence that neuron-to-glia signaling is mediated by ATP release from neurons. As an alternate hypothesis, retinal neurons could release a nonpurinergic transmitter that activates glia, causing a $\mathrm{Ca}^{2+}$-independent release of ATP from the glial cells. Released ATP could then act in an autocrine manner, evoking a glial $\mathrm{Ca}^{2+}$ increase.

Although neuron-to-glia signaling in the brain can be mediated by ATP (Bowser and Khakh, 2004), GABA (Kang et al., 1998), or acetylcholine (Araque et al., 2002), glutamate appears to be the principal neuron to glia transmitter in the brain (Schipke and Kettenmann, 2004). In contrast, in the retina, glutamate plays little, if any, role in neuron-to-glia signaling while ATP most likely mediates the response. It is unclear what accounts for this difference in signaling between the brain and the retina. One possible reason is that glutamate is tonically released from retinal neurons (Miller, 2001) and thus may not be well suited to function as the transmitter mediating neuron-glial communication.

\section{Adenosine potentiation of $\mathrm{Ca}^{2+}$ responses}

Light stimulation in the presence of adenosine or the adenosine agonist NECA elicits much larger Müller cell $\mathrm{Ca}^{2+}$ increases than those seen in control superfusate. This observation suggests that neuron-to-glia signaling in the retina is augmented under patho- logical conditions, when adenosine levels can rise significantly (Cunha, 2001). During cerebral ischemia, for instance, adenosine concentration can increase up to 85-fold above basal levels (Phillis et al., 1996; Latini et al., 1999; Parkinson et al., 2000). In the retina, hypoxia produces a $300 \%$ increase in extracellular adenosine levels (Ribelayga and Mangel, 2005). Even under physiological conditions, there are circadian and light-dependent variations in retinal adenosine levels. Adenosine concentration is highest at night and in the dark (Ribelayga and Mangel, 2005). Experiments in the present study were conducted during the day and in light-adapted retinas, in which adenosine levels and, thus, neuron-to-glia signaling would be expected to be minimum.

\section{Significance of neuron-to-glia signaling}

Bidirectional communication between neurons and glial cells has been demonstrated previously in brain slices (for review, see Fellin and Carmignoto, 2004; Newman, 2005). These interactions permit glial cells to modulate synaptic transmission and to directly alter the excitability of brain neurons. We demonstrated previously that Müller cells can modulate the excitability of neurons in the retina (Newman and Zahs, 1998; Newman, 2003a). The present study provides evidence that the reciprocal interaction, neuron-to-glia signaling, also occurs. The existence of twoway signaling between neurons and glia in the retina suggests that glia play an active role in modulating neuronal behavior in the retina, as they do in the brain.

Many questions concerning neuron-glia interactions in the retina remain to be addressed. This study demonstrates that neuron-to-glia signaling occurs in the isolated retina. It must be confirmed that signaling also occurs in vivo. In addition, several predictions arise from this study. First, the results suggest that amacrine cells and perhaps ganglion cell dendrites release ATP. Second, adenosine potentiation of neuron-to-glia signaling implies that signaling is augmented under pathological conditions. Finally, the existence of bidirectional signaling suggests that retinal Müller cells influence the light-evoked activity of retinal neurons in vivo. These predictions await future tests.

\section{References}

Aguado F, Espinosa-Parrilla JF, Carmona MA, Soriano E (2002) Neuronal activity regulates correlated network properties of spontaneous calcium transients in astrocytes in situ. J Neurosci 22:9430-9444.

Alloisio S, Cugnoli C, Ferroni S, Nobile M (2004) Differential modulation of ATP-induced calcium signalling by $\mathrm{A}_{1}$ and $\mathrm{A}_{2}$ adenosine receptors in cultured cortical astrocytes. Br J Pharmacol 141:935-942.

Araque A, Martin ED, Perea G, Arellano JI, Buno W (2002) Synaptically released acetylcholine evokes $\mathrm{Ca}^{2+}$ elevations in astrocytes in hippocampal slices. J Neurosci 22:2443-2450.

Blazynski C, Perez MT (1991) Adenosine in vertebrate retina: localization, receptor characterization, and function. Cell Mol Neurobiol 11:463-484.

Bowser DN, Khakh BS (2004) ATP excites interneurons and astrocytes to increase synaptic inhibition in neuronal networks. J Neurosci 24:8606-8620.

Cunha RA (2001) Adenosine as a neuromodulator and as a homeostatic regulator in the nervous system: different roles, different sources and different receptors. Neurochem Int 38:107-125.

Fellin T, Carmignoto G (2004) Neurone-to-astrocyte signalling in the brain represents a distinct multifunctional unit. J Physiol (Lond) 559:3-15.

Fields RD, Stevens B (2000) ATP: an extracellular signaling molecule between neurons and glia. Trends Neurosci 23:625-633.

Finkbeiner SM (1993) Glial calcium. Glia 9:83-104.

Hirase H, Qian L, Bartho P, Buzsaki G (2004) Calcium dynamics of cortical astrocytic networks in vivo. PLoS Biol 2:494-499.

Kang J, Goldman SA, Nedergaard M (1998) Astrocyte-mediated potentiation of inhibitory synaptic transmission. Nat Neurosci 1:683-692.

Karwoski CJ, Proenza LM (1977) Relationship between Müller cell re- 
sponses, a local transretinal potential, and potassium flux. J Neurophysiol 40:244-259.

Karwoski CJ, Proenza LM (1980) Neurons, potassium, and glia in proximal retina of Necturus. J Gen Physiol 75:141-162.

Keirstead SA, Miller RF (1995) Calcium waves in dissociated retinal glial (Müller) cells are evoked by release of calcium from intracellular stores. Glia 14:14-22.

Latini S, Bordoni F, Pedata F, Corradetti R (1999) Extracellular adenosine concentrations during in vitro ischaemia in rat hippocampal slices. $\mathrm{Br} \mathrm{J}$ Pharmacol 127:729-739.

Mikkelsen JD (1992) Visualization of efferent retinal projections by immunohistochemical identification of cholera toxin subunit B. Brain Res Bull 28:619-623.

Miller RF (2001) The physiology and morphology of the vertebrate retina. In: Retina (Ryan SJ, ed), pp 138-170. St. Louis: Mosby.

Neal M, Cunningham J (1994) Modulation by endogenous ATP of the lightevoked release of ACh from retinal cholinergic neurones. $\mathrm{Br} J \mathrm{Pharmacol}$ 113:1085-1087.

Nett WJ, Oloff SH, McCarthy KD (2002) Hippocampal astrocytes in situ exhibit calcium oscillations that occur independent of neuronal activity. J Neurophys 87:528-537.

Newman EA (1989) Potassium conductance block by barium in amphibian Müller cells. Brain Res 498:308-314.

Newman EA (1993) Inward-rectifying potassium channels in retinal glial (Müller) cells. J Neurosci 13:3333-3345.

Newman EA (2001a) Glia of the retina. In: Retina (Ryan SJ, ed), pp 89-103. St. Louis: Mosby.

Newman EA (2001b) Propagation of intercellular calcium waves in retinal astrocytes and Müller cells. J Neurosci 21:2215-2223.

Newman EA (2003a) Glial cell inhibition of neurons by release of ATP. J Neurosci 23:1659-1666.

Newman EA (2003b) New roles for astrocytes: regulation of synaptic transmission. Trends Neurosci 26:536-542.

Newman EA (2004) Glial modulation of synaptic transmission in the retina. Glia 47:268-274.

Newman EA (2005) Glia and synaptic transmission. In: Neuroglia (Kettenmann H, Ransom BR, eds), Oxford: Oxford UP.

Newman EA, Bartosch R (1999) An eyecup preparation for the rat and mouse. J Neurosci Methods 93:169-175.

Newman EA, Reichenbach A (1996) The Müller cell: a functional element of the retina. Trends Neurosci 19:307-312.

Newman EA, Zahs KR (1997) Calcium waves in retinal glial cells. Science 275:844-847.

Newman EA, Zahs KR (1998) Modulation of neuronal activity by glial cells in the retina. J Neurosci 18:4022-4028.
Nishizaki T (2004) ATP- and adenosine-mediated signaling in the central nervous system: adenosine stimulates glutamate release from astrocytes via $A_{2 a}$ adenosine receptors. J Pharmacol Sci 94:100-102.

Parkinson FE, Zhang YW, Shepel PN, Greenway SC, Peeling J, Geiger JD (2000) Effects of nitrobenzylthioinsine on neuronal injury, adenosine levels, and adenosine receptor activity in rat forebrain ischemia. J Neurochem 75:795-802.

Parri HR, Gould TM, Crunelli V (2001) Spontaneous astrocytic $\mathrm{Ca}^{2+}$ oscillations in situ drive NMDAR-mediated neuronal excitation. Nat Neurosci 4:803-812.

Pasti L, Volterra A, Pozzan T, Carmignoto G (1997) Intracellular calcium oscillations in astrocytes: a highly plastic, bidirectional form of communication between neurons and astrocytes in situ. J Neurosci 17:7817-7830.

Phillis JW, Smith-Barbour M, O'Regan MH (1996) Changes in extracellular amino acid neurotransmitters and purines during and following ischemias of different durations in the rat cerebral cortex. Neurochem Int 29:115-120.

Porter JT, McCarthy KD (1996) Hippocampal astrocytes in situ respond to glutamate released from synaptic terminals. J Neurosci 16:5073-5081.

Reifel Saltzberg JM, Garvey KA, Keirstead SA (2003) Pharmacological characterization of P2Y receptor subtypes on isolated tiger salamander Müller cells. Glia 42:149-159.

Ribelayga C, Mangel SC (2005) A circadian clock and light/dark adaptation differentially regulate adenosine in mammalian retina. J Neurosci 25:215-222.

Santos PF, Caramelo OL, Carvalho AP, Duarte CB (1999) Characterization of ATP release from cultures enriched in cholinergic amacrine-like neurons. J Neurobiol 41:340-348.

Schipke CG, Kettenmann H (2004) Astrocyte responses to neuronal activity. Glia 47:226-232.

Stevens B, Fields RD (2000) Response of Schwann cells to action potentials in development. Science 287:2267-2271.

Volterra A, Magistretti PJ, Haydon PG (2002) The tripartite synapse. Glia in synaptic transmission. New York: Oxford UP.

Wassle H (2004) Parallel processing in the mammalian retina. Nat Rev Neurosci 5:747-757.

Wright LL, Vaney DI (2004) The type 1 polyaxonal amacrine cells of the rabbit retina: a tracer-coupling study. Vis Neurosci 21:145-155.

Xin D, Bloomfield SA (1997) Tracer coupling pattern of amacrine and ganglion cells in the rabbit retina. J Comp Neurol 383:512-528.

Zenisek D, Henry D, Studholme K, Yazulla S, Matthews G (2001) Voltagedependent sodium channels are expressed in nonspiking retinal bipolarneurons. J Neurosci 21:4543-4550. 